\title{
Expression of matrix metalloproteinases MMP-2 and MMP-9 is altered during nephrogenesis in fetuses from diabetic rats
}

\author{
Jean-Paul Duong Van Huyen ${ }^{1,2}$, Mélanie Viltard ${ }^{1}$, Touria Nehiri ${ }^{1}$, Nicole Freund ${ }^{1}$, Marie-France Bélair ${ }^{1}$, \\ Cécile Martinerie $^{3}$, Brigitte Lelongt ${ }^{4}$, Patrick Bruneval ${ }^{1,2}$ and Martine Lelièvre-Pégorier ${ }^{1}$
}

Remodeling of extracellular matrix (ECM) is an important physiological feature of normal growth and development. Recent studies have emphasized the role of matrix metalloproteinases (MMP-2 and MMP-9) in normal mouse nephrogenesis. We have demonstrated previously in the rat that in utero exposure to maternal diabetes impairs renal development leading to a 30\% reduction in the nephron number. Transforming growth factor- $\beta 1$ (TGF- $\beta 1$ ) and connective tissue growth factor (CTGF) are known to mediate high glucose effects on matrix degradation. The aim of the present study was to address the expression of type IV collagenase and TGF- $\beta 1 /$ CTGF systems in rat kidney during normal development and after in utero exposure to maternal diabetes. Both MMP-2 and MMP-9 mRNA metanephric expressions and activities were dramatically downregulated in kidneys issued from diabetic fetuses and in metanephros cultured in the presence of high glucose concentration. TGF- $\beta 1$ and CTGF expressions were significantly enhanced in diabetic fetal kidneys and in high glucose cultured metanephroi. Conditioned media obtained from metanephroi grown with high glucose concentration upregulated functional TGF- $\beta$ activity in transfected ATDC5 cells. In conclusion, in impaired nephrogenesis resulting from in utero exposure to maternal diabetes, alteration of both type IV collagenase and TGF- $\beta 1 /$ CTGF systems may lead to abnormal remodeling of ECM, which may, in turn, induce defects in ureteral bud branching leading to the observed reduction in the nephron number with consequences later in life: progression of chronic renal disease and hypertension.

Laboratory Investigation (2007) 87, 680-689; doi:10.1038/labinvest.3700562; published online 14 May 2007

KEYWORDS: diabetes mellitus; nephrogenesis; extracellular matrix; metalloproteinase

The development of the kidney is based on reciprocal induction between two mesodermally derivated tissues. Morphogenesis starts when the ureteric bud (UB) invades the metanephric mesenchyme and initiates reciprocal induction. The mesenchyme induces the UB to grow and branch to form the collecting ducts. The UB, in turn, induces the mesenchyme to undergo a mesenchymal to epithelial conversion to form nephrons via a series of morphogenetic events (aggregation of mesenchyme to form renal vesicles then S-shaped bodies and finally mature glomeruli). ${ }^{1,2}$ Regulation of this process involves the participation of various DNAbinding proteins, that is, transcription factors, growth factors and their receptors, and proto-oncogenes acting as growth factor receptors. A constant remodeling of the extracellular matrix (ECM) is needed at the growing tips of the invading uretric bud to allow further branchings in the metanephric mesenchyme. ${ }^{3,4}$ Production of ECM-degrading enzymes is expectedly linked to metanephric development to regulate the expression of ECM protein and ECM-related proteins by proteolytic processing. This creates a gradient of all these molecules in strategic locations with spatiotemporal distribution. ${ }^{4}$ The ECM-degrading enzymes are collectively known as matrix metalloproteinases (MMPs) because their activity is dependent on the presence of metal ion, for example, $\mathrm{Zn}^{2+}$. The activity of MMPs is inhibited by tissue inhibitors of MMPs (TIMP-1-4). Among the MMPs, type IV collagenase MMP-2 and MMP-9 have been studied in normal nephrogenesis, mainly in the mouse and with conflicting results. ${ }^{4-12}$

\footnotetext{
${ }^{1}$ INSERM U652, IFR 58, Centre de recherche des Cordeliers, Université René Descartes (Paris 5), Paris, France; '2Laboratoire d'Anatomie Pathologique, Hôpital Européen Georges Pompidou, Université René Descartes (Paris 5), Paris, France; ${ }^{3}$ INSERM U515, Hôpital Saint-Antoine, Université Pierre et Marie Curie (Paris 6), Paris, France and ${ }^{4}$ INSERM U702, Hôpital Tenon, Université Pierre et Marie Curie (Paris 6), Paris, France

Correspondence: Dr J-P Duong Van Huyen, PhD, Laboratoire d'Anatomie Pathologique, Hôpital Européen Georges Pompidou, Université René Descartes, 20-40 rue Leblanc, Paris 75015, France. E-mail: jean-paul.duong-van-huyen@hop.egp.ap-hop-paris.fr

Received 04 January 2007; revised 05 March 2007; accepted 12 March 2007
} 
Diabetes is associated with a high incidence of congenital malformations including urogenital abnormalities. ${ }^{13,14}$ These congenital malformations result from developmental defects occurring in early organogenesis. They include genitourinary abnormalities that can be so severe as to cause renal agenesis. ${ }^{15}$ Using both streptozotocin (STZ)-induced diabetes and glucose infusion rat models, we have demonstrated that in utero exposure to hyperglycemia impairs nephrogenesis in fetuses. ${ }^{16}$ The previous study identifies maternal diabetes as a novel risk factor for inborn nephron deficit. According to recent works, a congenital nephron deficit, even moderate, is a risk factor for progression in patients with chronic renal disease and hypertension in adulthood. ${ }^{17-19}$

Increased deposition of ECM is the hallmark of diabetic complications in the adult kidney: ${ }^{20}$ diabetic glomerulosclerosis is characterized by accumulation of mesangial matrix that has been linked to a reduction in MMP activities (mainly MMP-2 activity). ${ }^{21-24}$ An effect of glucose on the in vitro regulation of type IV collagenase system has been clearly demonstrated in various cell systems. ${ }^{21,23,24}$ Recent studies have demonstrated the crucial role of both transforming growth factor- $\beta 1$ (TGF- $\beta 1$ ) and its downstream mediator, connective tissue growth factor (CTGF) in the glucose-induced dysregulation of MMP in experimental diabetic nephropathy. ${ }^{21,23-28}$ Little is known concerning the implication of MMP and TGF- $\beta 1 /$ CTGF systems in diabetic nephrogenesis. Several studies have reported that in vitro exposure of metanephroi to high glucose concentration causes alteration in extracellular components which may explain the dysmorphogenesis of the embryonic kidney. ${ }^{29,30}$ On the other hand, these authors have also shown that maternal diabetes increases the synthesis of ECM components in developing embryos. ${ }^{3}$ Altogether, these studies strongly suggest that maternal diabetes may induce an alteration of nephrogenesis via glucose-impaired ECM regulation.

Thus, the present study was performed to investigate the expression of type IV collagenase system and TGF- $\beta 1$ /CTGF system in rat metanephros during both normal and diabeticaltered nephrogenesis and in metanephros cultured in presence of high glucose concentration.

Our results show that type IV collagenase system is developmentally regulated in normal nephrogenesis and that its expression is altered during diabetic kidney development. This alteration is associated to an enhancement of TGF- $\beta 1 /$ CTGF system.

\section{MATERIALS AND METHODS Experimental Protocol}

Female Sprague-Dawley rats given free access to water and standard laboratory pellets (UAR Laboratory, Villemoison sur Orge, France), were caged overnight with a male and vaginal smears were taken the following morning. The day a positive smear was obtained was designated as day 0 of gestation. Pregnant females were made diabetic, as described previously, by a single injection of $40 \mathrm{mg} / \mathrm{kg}$ body weight of STZ (Sigma, Saint Quentin Fallavier, France). ${ }^{16}$ The experiments were performed in fetuses removed from anesthetized pregnant female rats on days $14,16,18$, and 20 of gestation. Metanephric kidneys were surgically removed from fetuses and were fixed in $4 \%$ formalin for histological and in situ hybridization studies. The experiments were conducted in accordance with the institutional guidelines and the recommendations for the care and use of laboratory animals put forward by the French Ministry of Agriculture.

Table 1 Primer list and characteristics

\begin{tabular}{|c|c|c|c|c|}
\hline$\beta$-actin & Sense & $5^{\prime}$-GGG ACG ATA TGG AGA AGA TाT & 315 & 61.1 \\
\hline \multirow[t]{2}{*}{ MMP-2 } & Sense & $5^{\prime}$-CCT GAA TAC TाT CTA TGG CTG C & 631 & 61.3 \\
\hline & Antisense & $5^{\prime}$-GTA TGT AGT GGA GCA CCA GAG C & & \\
\hline & Antisense & $5^{\prime}-\mathrm{GAC}$ GAA GGG GAA GAC GCA & & \\
\hline \multirow[t]{2}{*}{ TIMP-1 } & Sense & 5'-CAT CGA GAC CAC CTT AT & 193 & 60.4 \\
\hline & Antisense & 5'-CAC CCC ACA GCC AGC ACT ATA & & \\
\hline \multirow[t]{2}{*}{ TIMP-2 } & Sense & $5^{\prime}-\mathrm{CAA}$ AGC AGT GAG CGA GAA GG & 393 & 61.6 \\
\hline & Antisense & 5'-ACC CAG TCC ATC CAG AGG GA & & \\
\hline CTGF & Antisense & 5'-ATG ACA ATG ACA CAC GGT TCT C & & \\
\hline
\end{tabular}




\section{Histology and Immature (S-Shaped Bodies) and Mature Glomeruli Counts}

Longitudinal frontal renal cross sections were taken through the hilus and embedded in paraffin. A total of $4-\mu \mathrm{m}$-thick serial sections were cut and stained with hematein and eosin for morphological analysis. The total numbers of immature (S-shaped bodies) and mature glomeruli were determined in kidneys of fetuses at gestational day 18 on whole longitudinal sections taken through the hilus, assuming the results would be representative of the number of nephrons within the entire kidney. ${ }^{31}$ The initial stages of glomerular development (renal vesicles) were excluded from this counting. Glomeruli were considered as mature when they clearly demonstrated both distinct Bowman's spaces and vascularized floculi, regardless of the glomerular width. The mean number of immature and mature glomeruli was counted one by one, by scanning the entire kidney sections (in respectively six and eight kidneys from control and diabetic mothers) by three different investigators who were unaware of the specimen groups.

\section{Metanephric Organ Culture}

Embryonic rat kidneys were microdissected at 14 days of gestation and cultured as described previously. ${ }^{32}$ Briefly, the metanephroi were placed on a $0.8 \mu \mathrm{M}$ polycarbonate filter (Millipore, Saint-Quentin-en-Yveline, France) flotting on a defined serum free medium and incubated for 6 days in $35 \mathrm{~mm}$ Petri dishes at $37^{\circ} \mathrm{C}$ in a humidified incubator containing $5 \% \mathrm{CO}_{2}$. One metanephros from each fetus was grown in control medium, and the controlateral metanephros was grown in the same medium with glucose added $(14 \mathrm{mM})$. All media were changed daily. Nephrons formed in vitro were visualized after labeling the explanted metanephroi as described previously ${ }^{16}$ using specific lectins, the helix pomatia agglutinin coupled to fluorescein, which stains tubules and glomeruli and peanut agglutinin (PNA) coupled to rhodamine, which stains only glomeruli.

\section{Quantitative RT-PCR}

Quantitative RT-PCR was performed as described previously. ${ }^{33}$ Total RNA was isolated from the kidneys of different embryonic days with Tri-reagent (Invitrogen). Before reverse transcription, all RNA samples $(2 \mu \mathrm{g})$ were freed of any contaminating DNA by treatment with a RNase-free DNase I according to the manufacturer protocol (Invitrogen). First-strand cDNA synthesis was primed by Superscipt II reverse transcriptase (200 U) with $250 \mathrm{ng}$ random primers. Negative control tubes were performed to ensure the absence of DNA contamination. Resulting single stranded cDNA was used as a starting material for quantitative assay of the transcript by real-time PCR. Primer pairs used for cDNA amplifications are listed in Table 1 . The quality and specificity of the resulting amplified PCR fragment were also carefully checked. Quantitative PCR experiments, carried out to determine mRNA concentrations, were performed on a Light Cycler apparatus (Roche Diagnostics). SYBR Green dye was used as a reporter for detection according to protocols from Roche Diagnostics. Reactions were conducted in glass capillaries, subjected to a 10 -min initial hot-start activation of the Taq polymerase at $95^{\circ} \mathrm{C}$, followed by an adapted cycle numbers of amplification (Table 1).

Final data were expressed as the ratio between the amount of MMP-2, MMP-9, TIMP-1, TIMP-2, TGF- $\beta 1$, and CTGF transcripts and the amount of $\beta$-actin transcript. All calculations were made with the Light Cycler software (version 3, Roche Diagnostics). After running the experiments, two types of quality controls were carried out. First, final products were submitted to a Light Cycler built-in renaturingdenaturing thermal program. Fusion curves obtained during this step gave confirmation of the homogeneity of the amplified fragments. Second, all the amplified products were electrophoresed on an agarose gel for visual inspection.

\section{In Situ Hybridization}

In situ hybridization was performed as described previously. ${ }^{34}$ Following fixation in formalin, tissues were embedded in

Table 2 Maternal blood glucose concentration and insulinemia, number of fetuses and mean fetal body weight on gestational days $14,16,18$, and 20

\begin{tabular}{|c|c|c|c|c|c|}
\hline $\begin{array}{l}\text { Days of } \\
\text { gestation }\end{array}$ & Groups & $\begin{array}{l}\text { Maternal blood glucose } \\
\text { concentration }(\mathrm{mmol} / \mathrm{l})\end{array}$ & $\begin{array}{l}\text { Maternal insulinemia } \\
\quad(\mathrm{pmol} / \mathrm{l})\end{array}$ & $\begin{array}{c}\text { Number of fetuses } \\
\text { by litter }\end{array}$ & $\begin{array}{l}\text { Mean fetal body } \\
\text { weight (mg) }\end{array}$ \\
\hline & $\operatorname{STZ}(n=14)$ & $23.1 \pm 3.2^{* * * *}$ & $122.1 \pm 3.2^{* * * *}$ & $13.5 \pm 2.1$ & $144.9 \pm 7.8^{*}$ \\
\hline 16 & Control $(n=3)$ & $5.7 \pm 0.5$ & $175.2 \pm 4.1$ & $11.7 \pm 2.5$ & $458.3 \pm 6.0$ \\
\hline & $\mathrm{STZ}(n=3)$ & $22.8 \pm 1.7^{* * *}$ & $126.1 \pm 4.2^{* * *}$ & $15 \pm 1.7$ & $1270 \pm 70^{*}$ \\
\hline \multirow[t]{2}{*}{20} & Control $(n=3)$ & $5.3 \pm 0.7$ & $175.1 \pm 4.1$ & $10.7 \pm 3.2$ & $3640 \pm 90$ \\
\hline & $\mathrm{STZ}(n=3)$ & $22.3 \pm 2.6^{* * *}$ & $128.2 \pm 2.3^{* * *}$ & $12.7 \pm 4.7$ & $3380 \pm 150^{*}$ \\
\hline
\end{tabular}

${ }^{\star} P<0.05,{ }^{* * *} P<0.001,{ }^{* * * *} P<0.0001$ compared to control. 
paraffin. Deparaffinized $5-\mu \mathrm{m}$-thick sections were digested for $15 \mathrm{~min}$ at $37^{\circ} \mathrm{C}$ with $15 \mu \mathrm{g} / \mathrm{ml}$ protease $\mathrm{K}$ (Sigma) in a buffer containing $20 \mathrm{mM}$ Tris- $\mathrm{HCl}, \mathrm{pH} 7.5$, and $2 \mathrm{mM} \mathrm{CaCl}_{2}$. MMP-2 and MMP-9 cDNA probes were labeled with ${ }^{35} \mathrm{~S}$ dCTP using Megaprime DNA labeling system (Amersham, Les Ulis, France). Hybridization with ${ }^{35} \mathrm{~S}$-labeled rat probes $(0.2 \mu \mathrm{g} / \mathrm{ml})$ was performed overnight at $45^{\circ} \mathrm{C}$ in $40 \%$ formamide, $4 \times$ SSC, $10 \%$ dextran, $1 \times$ Denhardt, $0.8 \mathrm{mg} / \mathrm{ml}$ yeast tRNAs, and $0.5 \mathrm{mg} / \mathrm{ml}$ denatured salmon sperm DNA. Sections were washed two times at $45^{\circ} \mathrm{C}$ for $15 \mathrm{~min}$ in $40 \%$ formamide and $4 \times \mathrm{SSC}$, once at $60^{\circ} \mathrm{C}$ for $30 \mathrm{~min}$ in $4 \times \mathrm{SSC}$, and three times at room temperature for $20 \mathrm{~min}$ in $2 \times \mathrm{SSC}$. After dehydration, sections were dipped into NTBII autoradiographic emulsion (Kodak, Rochester, NY, USA) and exposed at $4^{\circ} \mathrm{C}$ for 21 days. Slides were finally immersed in D19 developer (Kodak), fixed in A44 Kodak and counterstained with hematoxylin and eosin. Control slides $(50 \mu \mathrm{g} /$ $\mathrm{ml}$ ) were treated by RNase A (Sigma) at $37^{\circ} \mathrm{C}$ for $30 \mathrm{~min}$ in $2 \times$ SSC and washed at room temperature for $15 \mathrm{~min}$ in $2 \times$ SSC before the hybridization.

\section{Substrate Gel Electrophoresis (Zymography)}

In kidneys from fetuses of 14,16, 18, and 20 days day post coitus $(\mathrm{dpc})$ issued from control and diabetic mothers, metalloproteinases were detected and characterized by zymography as described previously. ${ }^{9}$ The gelatinolytic activity of MMP-2 and MMP-9 was demonstrated by zymography. Kidney proteins were solubilized in lysis buffer $(50 \mathrm{mM}$ Tris, $150 \mathrm{mM} \mathrm{NaCl}, \mathrm{NP}-401 \%, 10 \mathrm{mM}$ EDTA, $0.5 \%$ sodium deoxycholate, $0.1 \%$ SDS, $\mathrm{pH} 8$ ) overnight at $4^{\circ} \mathrm{C}$. About $20 \mu \mathrm{g}$ of protein, measured by a Bio-Rad protein assay (Bio-Rad Laboratories, München, Germany) was loaded on 8\% SDS-polyacrylamide (Merck, Darmstadt, Germany) and the gels were co-polymerized with $1 \mathrm{mg} / \mathrm{ml}$ of gelatin or type IV collagen (Sigma). Electrophoresis was performed under non-reducing conditions at $25 \mathrm{~mA}$. Gels were washed two times for $30 \mathrm{~min}$ in $2.5 \%$ Triton X-100 to remove SDS, incubated in substrate buffer $(50 \mathrm{mM}$ Tris- $\mathrm{HCl}, 5 \mathrm{mM} \mathrm{CaCl}$, $\left.1 \mu \mathrm{M} \mathrm{ZnCl}_{2}, 0.01 \% \mathrm{NaN}_{3}, \mathrm{pH} 7.5\right)$ overnight at $37^{\circ} \mathrm{C}$, stained in 2.5\% Coomassie Blue G (Sigma-Aldrich, St Louis, MI, USA) prepared in $50 \%$ methanol, $10 \%$ acetic acid for $30 \mathrm{~min}$ at room temperature and destained three times for $15 \mathrm{~min}$ in buffer composed of $30 \%$ methanol and $1 \%$ acetic acid. The presence of metalloproteinases was indicated by an unstained proteolytic zone of the substrate. The identity of MMP-2 and MMP-9 was assessed by their respective molecular weight and by using conditioned media from principal cell line. ${ }^{35}$

\section{Functional Activity of TGF- $\beta$}

Functional activity of TGF- $\beta 1$ was performed as described previously. ${ }^{36}$ ATDC5 cells in a six-well plates $\left(10^{5}\right.$ cells per well) were transfected in serum-free medium using FuGENE (Roche) as described in the user's manual. For reporter assays, $0.5 \mu \mathrm{g}$ of TGF- $\beta$ specific responsive promoter (CAGA) 9-MLP-Luc, (a gift from JM Gauthier), was co-transfected with $0.1 \mu \mathrm{g}$ of pCMV $\beta$-galactosidase as an internal transfection control (Clontech). After $24 \mathrm{~h}$ of transfection, serum-starved cells were treated for an additional $24 \mathrm{~h}$ period with conditioned medium, obtained from metanephroi cultured with or without glucose. Conditioned medium from metanephric organ culture was acidified according to McCormick et $a l^{37}$ to reveal TGF- $\beta$ activities. Luciferase and $\beta$-galactosidase activities were assayed using kits from

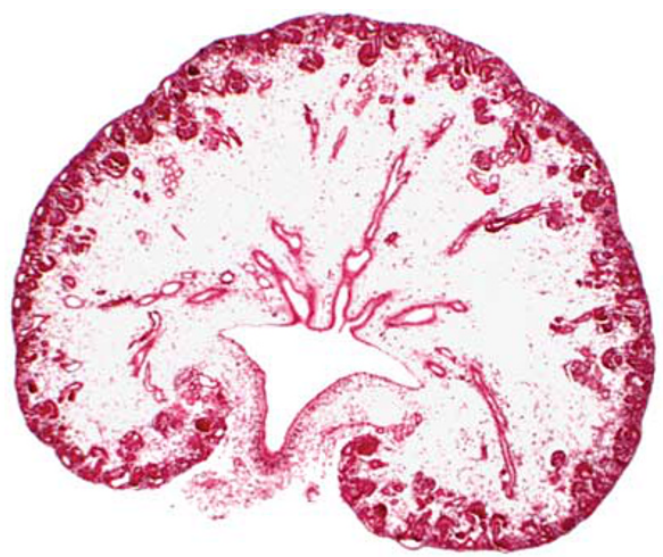

b
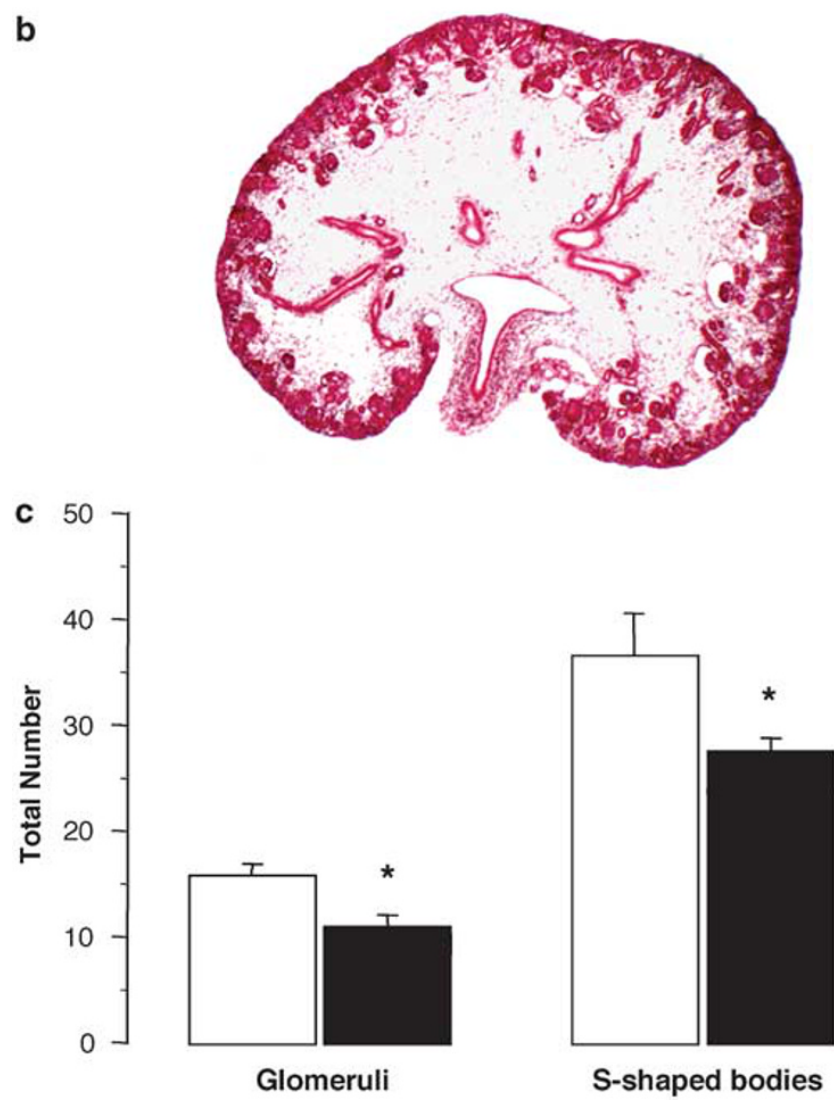

Figure 1 Representative kidneys of fetuses from control (a) and diabetic (b) rats on day 18 of gestation. Hematein and eosin. Panel c illustrated means of S-shaped bodies and glomeruli counts on kidney tissue sections from control (open bars, $n=6$ ) and diabetic (black bars, $n=8$ ) rats. Values are means \pm s.e.m. ${ }^{\star} P<0.05$. 
Promega and Perkin Elmer Life Sciences (Galacto-Star system). For each experiment performed on two separate occasions, conditioned media from three different metanephroi were pooled and the incubation was performed in triplicate.

\section{Statistical Analysis}

Data are presented as means \pm s.e.m. Differences between control and hyperglycemic groups were compared by Student's unpaired $t$-test, except in the case of data from metanephric organ cultures in which paired $t$-tests were used. The threshold of significance was taken to be $P<0.05$.

\section{RESULTS}

STZ-Induced Diabetic Rats and Histological Assessment of Diabetic Impaired Nephrogenesis

As shown in Table 2, the mean maternal plasma glucose and insulin concentrations in STZ group remained constant and was about three times higher for glucose (STZ group:
$22.9 \pm 0.1 \mathrm{mmol} / \mathrm{l}, n=23$ vs control group: $5.5 \pm 0.1 \mathrm{mmol} / \mathrm{l}$, $n=27$ ); and about $30 \%$ lower for insulinemia (STZ group: $124.9 \pm 1.3 \mathrm{mmol} / \mathrm{l}, \quad n=23$ vs control group: $173.6 \pm 1.7 \mathrm{pmol} / \mathrm{l}, n=27)$, respectively. Gestation occurred normally. The number of fetuses by litter was similar in the two groups. The mean body weights of fetuses from STZ mothers were reduced by about $10 \%$ as compared to controls. As illustrated in Figure 1, we confirmed the alteration of nephrogenesis reported previously using this animal model in 18-day-old fetuses from STZ mothers of the present study. ${ }^{16}$ Kidneys from STZ fetuses (panel b) were slightly smaller than their normal counterpart (panel a). The number of immature ( $\mathrm{S}$-shaped bodies) and mature glomeruli per kidney section was significantly lower in the STZ fetuses (S-shaped bodies: $26.3 \pm 1.3$ in STZ $(n=5) \quad$ vs $35.8 \pm 4.0 \quad P<0.05$ in control $(n=8)$; mature glomeruli: $10 \pm 1.1$ in STZ $(n=5)$ vs $15.9 \pm 1.1$ in control $(n=8), P<0.05)$.
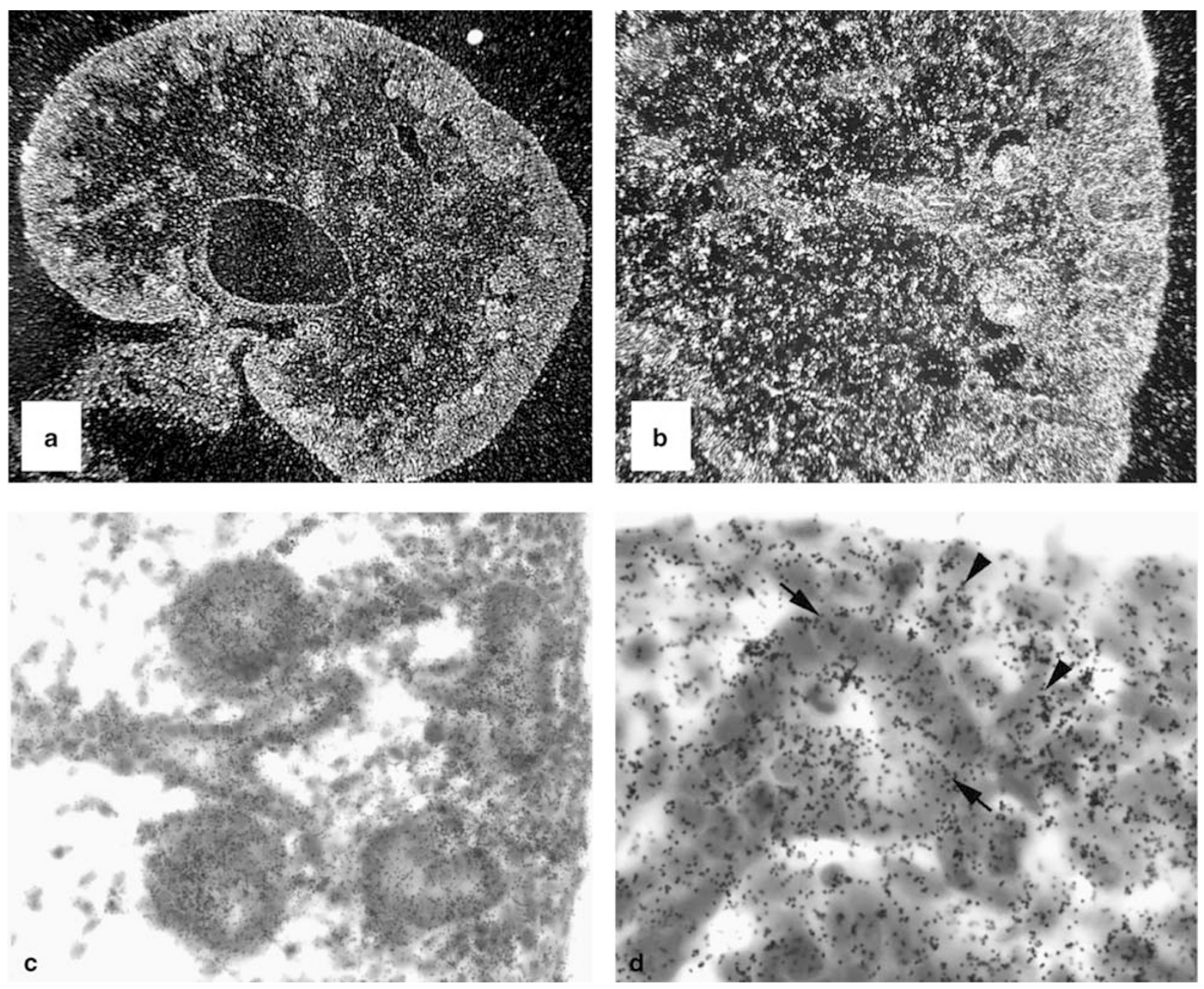

Figure 2 Representative in situ hybridization with rat MMP- $2{ }^{35}$ S-labeled cDNA probe in fetal kidneys from control rats on day 18 of gestation. Hybridization signal is mainly present in the cortex (a and b), where both epithelial and mesenchymal structures are labeled (c). In the nephrogenic zone (d), a strong signal was observed in both UB (arrows) and condensated mesenchyme (arrowheads). 

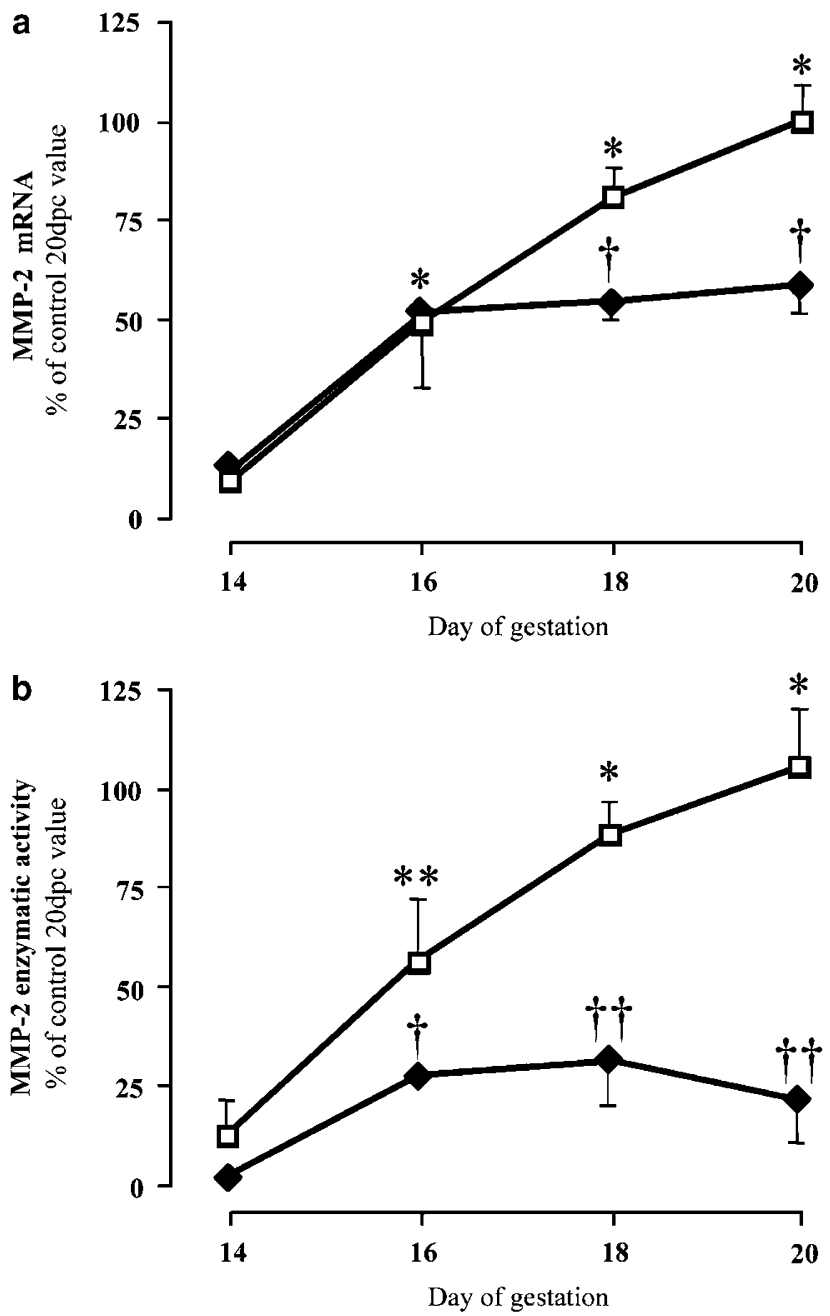

Figure 3 Analysis of MMP-2 during normal and diabetic kidney development. Expression pattern (a) and enzymatic activity (b) of MMP-2 in control (open squares) and diabetic (black diamonds) kidneys (14-20 dpc). Values are expressed as a percentage of $20 \mathrm{dpc}$ control values and represent the mean of four experiments. ${ }^{*} P<0.05$ and ${ }^{*} P<0.01$ compared with the precedent stage and ${ }^{\dagger} P<0.05$ and ${ }^{\dagger \dagger} P<0.01$ compared with age-matched control fetuses.

\section{Altered Expression of Type IV Collagenase System during Diabetic-Altered Nephrogenesis}

In control fetal rat kidney (gestational day 18), in situ hybridization (Figure 2) shows that MMP-2 mRNA expression was mainly present in the nephrogenic zone with a strong expression in the epithelial structure, the UB and the condensed mesenchyme. Despite several attempts, we failed, with our labeled probe specific of MMP-9 mRNA, to localize the expression of MMP-9 in the fetal kidney (data not shown). This may be probably due to the very low level of MMP-9 mRNA present in fetal metanephroi.

Figures 3-5 depict the modulation of type IV collagenase system expression in 14-20 dpc kidneys from control (open squares) and STZ fetuses (black diamonds).
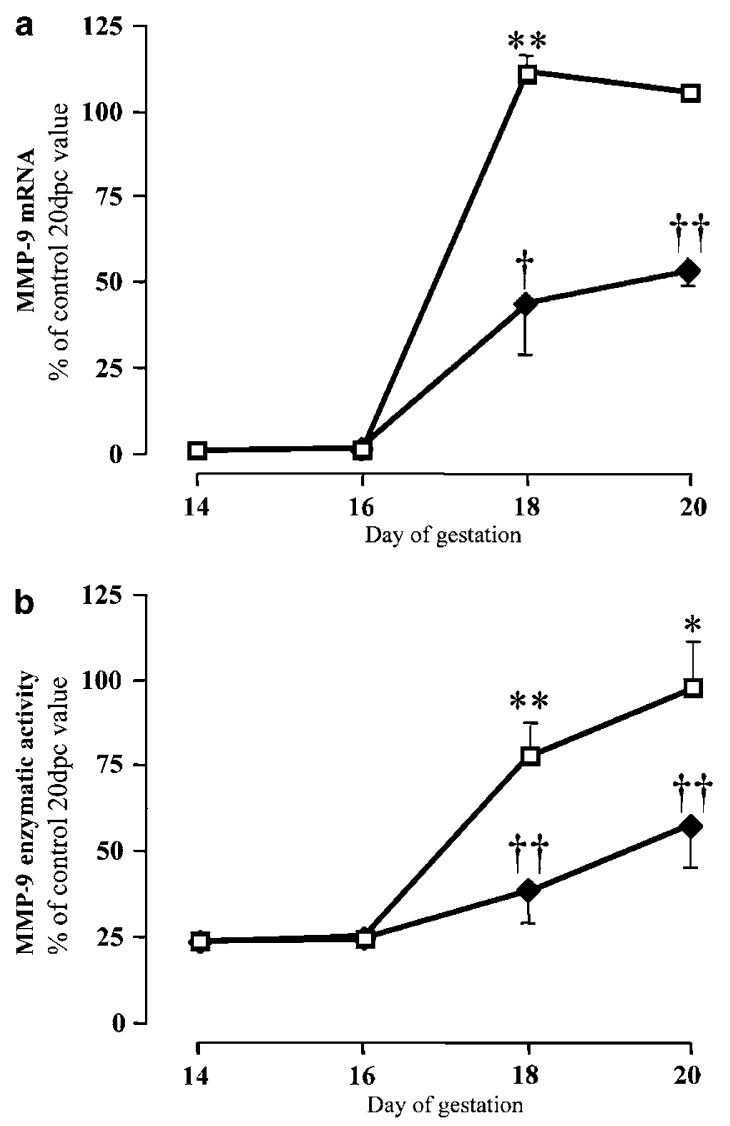

Figure 4 Analysis of MMP-9 during normal and diabetic kidney development. Expression pattern (a) and enzymatic activity (b) of MMP-9 in control (open squares) and diabetic (black diamonds) kidneys (14-20 dpc). Values are expressed as a percentage of $20 \mathrm{dpc}$ control values and represent the mean of four experiments. ${ }^{\star} P<0.05$ and ${ }^{* *} P<0.01$ compared with the precedent stage and ${ }^{\dagger} P<0.05$ and ${ }^{\dagger \dagger} P<0.01$ as compared with age-matched control fetuses.

During normal rat nephrogenesis (Figure 4, open squares) MMP-2 and MMP-9 mRNA and functional activities are strongly increased. In kidneys of STZ fetuses a significant reduction is observed: MMP-2 and MMP-9 expressions were reduced by $50 \%$ at $20 \mathrm{dpc}$ as compared to control values. Currently, MMP-2 enzymatic activity collapsed, representing less than one-fifth of control value. Localization of MMP-2 mRNA expression in kidneys of STZ fetuses was similar to that observed in controls (data not shown).

mRNA expressions of TIMP-2 and TIMP-1, MMP-2 and MMP-9 inhibitors, respectively, were unchanged between control and diabetic groups (Figure 5). The expression of TIMP-2 was constant during nephrogenesis while that of TIMP-1 was increased. 

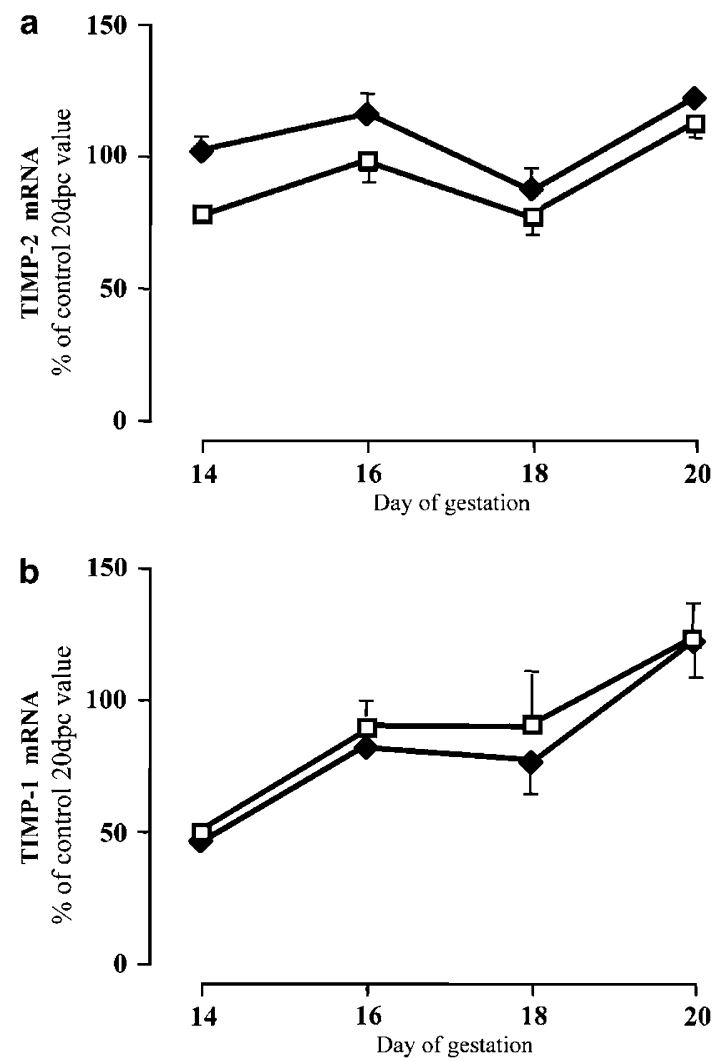

Figure 5 Analysis of TIMP-2 and TIMP-1 during normal and diabetic kidney development. Expression pattern (14-20 dpc) of TIMP-2 (a) and TIMP-1 (b) in control (open squares) and diabetic (black diamonds) kidneys. Values are expressed as a percentage of $20 \mathrm{dpc}$ control values and represent the mean of four experiments. ${ }^{*} P<0.05$ and ${ }^{* *} P<0.01$ compared with the precedent stage; and ${ }^{\dagger} P<0.05$ and ${ }^{\dagger} P<0.01$ compared with age-matched control fetuses.

\section{Decreased Expression of Type IV Collagenase System in Metanephric Organ Culture in Response to High Glucose Concentration}

Addition of glucose at high concentration in culture medium $(14 \mathrm{mM})$ strongly impaired in vitro metanephric growth (Figure 6). Both MMP-2 and MMP-9 mRNA levels were significantly reduced in this latter condition while expression of TIMP-2 and TIMP-1 were similar in both culture conditions.

\section{Hyperglycemia Enhances the Expression of Both TGF- $\beta 1$ and CTGF in Fetal Kidney}

A new set of experiments was then designed to address the involvement of TGF- $\beta 1$ and CTGF in diabetic nephrogenesis. Because the role of TGF- $\beta 1$ has been clearly demonstrated in UB division, we assessed-in metanephroi obtained from control and STZ fetuses-the expression of TGF- $\beta 1$ and CTGF at $16 \mathrm{dpc}$, a stage when UB branching is prominent. Results show that at this stage, maternal hyperglycemia strongly upregulated the expression of both TGF- $\beta 1$ and
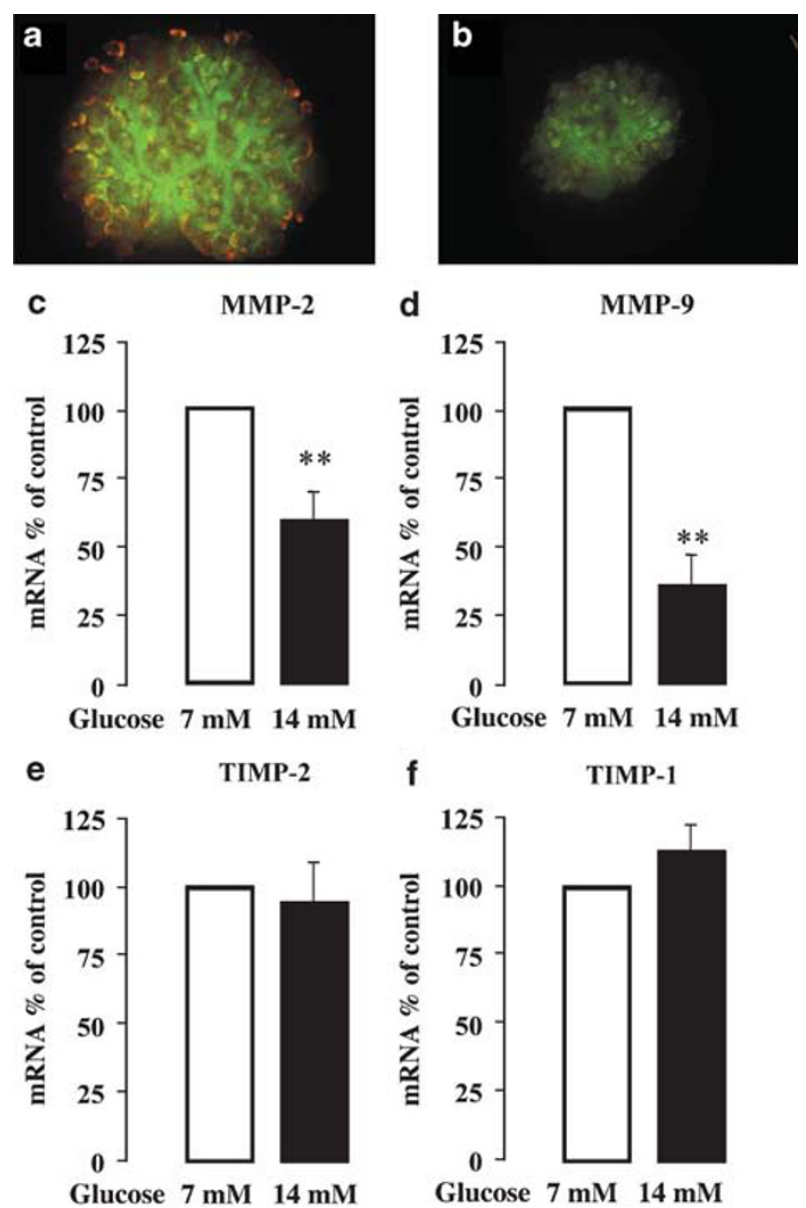

Figure 6 Analysis of type IV collagenase system during metanephroi development in vitro. Explanted metanephroi from 14-day-old embryos were cultured with $7 \mathrm{mM}$ (a and open bars) or $14 \mathrm{mM}$ (b and black bars) glucose. Metanephroi development was assessed by lectin histochemistry, using PNA and dolichos biflorus agglutinin labeling ( $\mathbf{a}$ and $\mathbf{b}$ ). The expression of MMP-2 (c), MMP-9 (d), TIMP-2 (e) and, TIMP-1 (f) in metanephric explants cultivated with $7 \mathrm{mM}$ (open bars) or $14 \mathrm{mM}$ (black bars) glucose were assessed by quantitative RT-PCR. Histograms represent quantification of mRNA expressed as a percentage of control values (means \pm s.e.m. from four independent experiments). ${ }^{* *} P<0.05$ as compared to control value.

CTGF (Figure 7a), in parallel with the decreased activity of MMP-2 but without alteration of MMP-9 activity (see Figures 2 and 4). We then studied in cultured metanephroi the expression of TGF- $\beta 1$ and CTGF in vitro (panel b). In high glucose concentration medium, quantitative RT-PCR showed a strong enhancement of TGF- $\beta 1$ and CTGF expression. Finally, to assess whether the TGF- $\beta 1$ upregulated mRNA expression could result in higher TGF- $\beta$ potential activity under these culture conditions, we used a promoter reporter bioassay. Compared to the control, the conditioned medium obtained from metanephros cultured with high glucose concentration indeed increased to a higher extent the luciferase activity driven by a TGF- $\beta$-specific responsive promoter (Figure 7c). 


\section{DISCUSSION}

The present study describes the expression of type IV collagenase and TGF- $\beta 1 /$ CTGF systems during rat normal and diabetic-altered nephrogenesis.

Our results show that the expression and functional activity of MMP-2, MMP-9, and TIMP-1 and TIMP-2 inhibitors are regulated in normal rat nephrogenesis and that MMP-2 and MMP-9 expressions are altered during kidney development in STZ fetuses. Both TGF- $\beta 1$ and CTGF metanephric expressions are also significantly enhanced in vivo by exposure to maternal diabetes and in vitro in the presence of high concentration of glucose in organotypic culture.

Although the role of ECM-degrading enzymes in organotypical epithelial-mesenchymal interaction was originally proposed more than three decades ago, ${ }^{38,39}$ recent evidence concerning their implication in nephrogenesis has only been found within the last few years, with conflicting results. Our results strongly support the crucial role of type IV collagenase system during nephrogenesis in the rat suggested by others in mice and in in vitro models. ${ }^{4-12}$ We found that both MMP-2 and MMP-9 expression and activity rise in the fetal kidney throughout normal gestation. Similar results have been reported in mice. ${ }^{7}$ In vitro their levels decrease during the postnatal period, suggesting that their potential role in the organogenesis of the kidney is confined to the embryonic period. ${ }^{9}$ MMP-2 expression in normal rat metanephros increases continuously while MMP-9 expression, nearly undetectable at 14 and $16 \mathrm{dpc}$, strongly increases in late nephrogenesis. We also show that TIMP-2 expression is present throughout the whole nephrogenesis and at high levels since $14 \mathrm{dpc}$. This result is in accordance with the presence of TIMP-2 in cell lines derived from $13 \mathrm{dpc}$ rat metanephros. ${ }^{6}$ TIMP-1 expression during nephrogenesis follows MMP-9 levels.

In situ hybridization in $18 \mathrm{dpc}$ rat metanephroi shows that MMP-2 mRNA expression is mainly present in the nephrogenic zone in the epithelial structures (UB) and in the condensed mesenchyme, a structure that undergoes an epithelial conversion to form nephrons. This pattern of distribution strongly suggests that this system is involved in epithelial-mesenchymal interactions. ${ }^{10}$ Sakurai and Nigam ${ }^{40}$ and Sakurai et $a l^{41}$ reported a parallel increase (or fall) in the MMP-2 mRNA expression with stimulation (or inhibition) of branching morphogenesis under the influence of TGF- $\beta$ or of epidermal growth factor receptor ligands. Furthermore, Pohl et $a l^{11}$ have recently reported that metanephric mesenchyme cell-derived conditioned medium alters the transcription of MMP-2, MMP-3, MMP-9, MT1-MMP, and TIMP-2 along with the changes in UB branching morphogenesis. Moreover, treatment of mouse metanephric explants by MMP-2 and MT-1-MMP antisense oligodeoxynucleotides results in the reduction of embryonic metanephros size and in dysmorphogenic changes of the UB, both effects that were partially reversed by co-incubation with TIMP-2 antisense oligonucleotides. ${ }^{7}$ MMP-9, expressed in the metanephros,
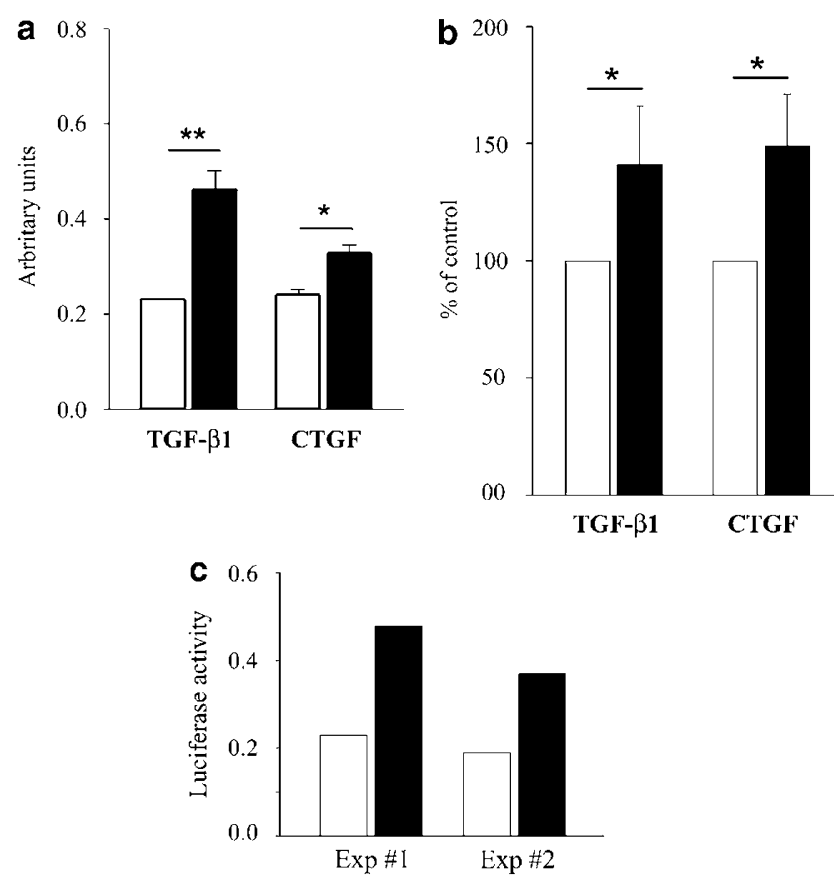

Figure 7 Analysis of TGF- $\beta 1$ and CTGF during metanephroi development. In vivo expression pattern of TGF- $\beta 1$ and CTGF was assessed by quantitative RT-PCR in $16 \mathrm{dpc}$ metanephroi obtained from control rats (a, open bars) and from diabetic mothers (black bars). In vitro, the expression of TGF- $\beta 1$ and CTGF (b) in metanephric explants cultivated with $7 \mathrm{mM}$ (open bars) or $28 \mathrm{mM}$ (black bars) glucose were assessed by quantitative RT-PCR. Histograms represent quantification of mRNA expressed as percentage of control values in paired metanephroi (mean \pm s.e.m. from four independent experiments). ${ }^{*} P<0.05$ as compared to control value. (c) Conditioned media from the metanephroi cultivated in high glucose condition upregulate TGF- $\beta$ activity in ATDC5 cells transfected with the TGF- $\beta$ responsive promoter construct (CAGA)9-MLP-Luc (results from two independent experiments). ${ }^{* *} P<0.01$.

has been shown to play a role in the organogenesis of the kidney in vitro. ${ }^{9}$ Here, we were unable to localize MMP-9 transcript, probably because of its very low level of expression as illustrated by quantitative RT-PCR experiments in which a high number of cycles were needed to obtain a signicative amplification.

Our major result is that type IV collagenase system is decreased in altered diabetic nephrogenesis. Transcription levels and activities of MMP-2 and MMP-9 are strongly reduced in fetal metanephric kidneys issued from STZ-induced diabetic rats. Furthermore, increasing glucose concentration in rat metanephric organ culture media results in a dramatic reduction of MMP-2 and MMP-9 expression within the explant together with an impairment of both explant growth and UB branching. Taken together, these two sets of experiments strongly suggest that impaired type IV collagenase system is involved in diabetic altered nephrogenesis, through abnormal ECM turnover leading to decreased UB branching.

In adult diabetic nephropathy, alteration of type IV collagenase system has been clearly observed. ${ }^{42}$ A regulation of collagenase type IV system by TGF- $\beta /$ CTGF system has 
recently been of glomerulosclerosis in diabetes. ${ }^{23,27}$ Furthermore in vitro studies have demonstrated that high glucose concentration can alter the expression of some MMPs and increase the expression of TIMPs in renal cells. ${ }^{21,23,24}$ In fetal kidney, TGF- $\beta 1$ mRNA has been localized in the UB and in the differentiating mesenchyme and is crucial for the branching of the UB. ${ }^{40,43-47}$ In the present study, we clearly demonstrate for the first time that hyperglycemia increases both in vivo and in vitro the expression of TGF- $\beta 1$ and of CTGF in renal tissue obtained from diabetic fetuses and from metanephroi cultivated with high glucose concentration. In addition, we show that conditioned medium taken from metanephroi cultured in high glucose concentration increases TGF- $\beta$ responsive promoter activity in cells transfected with reporter construct (CAGA)9-MLP-Luc. This indicates that the enhancement of TGF- $\beta 1$ mRNA expression results in enhancement of functional TGF- $\beta$. These observations are consistent with recent data ${ }^{25}$ reporting that CTGF expression is increased by glucose in renal epithelial cells and that this increase is mediated by TGF- $\beta$. Altogether these results strongly suggest a role of TGF- $\beta$ and CTGF in the alteration of kidney development during gestational diabetes. Therefore several mechanisms, either direct or ECM mediated might underly the inhibitory effect of TGF- $\beta$ and CTGF on nephrogenesis during maternal diabetes. ${ }^{4,48}$

1. Horster MF, Braun GS, Huber SM. Embryonic renal epithelia: induction, nephrogenesis, and cell differentiation. Physiol Rev 1999;79:11571191.

2. Saxen $\mathrm{L}$, Sariola $\mathrm{H}$, Lehtonen E. Sequential cell and tissue interactions governing organogenesis of the kidney. Anat Embryol (Berl) 1986;175:1-6.

3. Kanwar Y, Liu Z, Wallner E. Influence of glucose on murine metanephric development and proteoglycans: morphologic and biochemical studies. Lab Invest 1997;76:671-681.

4. Kanwar YS, Wada J, Lin S, et al. Update of extracellular matrix, its receptors, and cell adhesion molecules in mammalian nephrogenesis. Am J Physiol 2004;286:F202-F215.

5. Andrews KL, Betsuyaku T, Rogers $S$, et al. Gelatinase B (MMP-9) is not essential in the normal kidney and does not influence progression of renal disease in a mouse model of Alport syndrome. Am J Pathol 2000;157:303-311.

6. Barasch J, Yang J, Qiao J, et al. Tissue inhibitor of metalloproteinase-2 stimulates mesenchymal growth and regulates epithelial branching during morphogenesis of the rat metanephros. J Clin Invest 1999:103:1299-1307.

7. Kanwar $\mathrm{Y}$, Ota K, Yang $\mathrm{Q}$, et al. Role of membrane-type matrix metalloproteinase 1 (MT-1-MMP), MMP-2, and its inhibitor in nephrogenesis. Am J Physiol 1999;277(Renal Physiol 46):F934-F947.

8. Legallicier B, Trugnan G, Murphy G, et al. Expression of the type IV collagenase system during mouse kidney development and tubule segmentation. J Am Soc Nephrol 2001;12:2358-2369.

9. Lelongt B, Trugnan G, Murphy G, et al. Matrix metalloproteinases MMP2 and MMP9 are produced in early stages of kidney morphogenesis but only MMP9 is required for renal organogenesis in vitro. J Cell Biol 1997:136:1363-1373.

10. Ota K, Stetler-Stevenson WG, Yang Q, et al. Cloning of murine membrane-type-1-matrix metalloproteinase (MT-1-MMP) and its metanephric developmental regulation with respect to MMP-2 and its inhibitor. Kidney Int 1998;54:131-142.

11. Pohl M, Sakurai H, Bush KT, et al. Matrix metalloproteinases and their inhibitors regulate in vitro ureteric bud branching morphogenesis. Am J Physiol Renal Physiol 2000;279:F891-F900.
12. Reponen $\mathrm{P}$, Sahlberg $\mathrm{C}$, Huhtala $\mathrm{P}$, et al. Molecular cloning of murine 72-kDa type IV collagenase and its expression during mouse development. J Biol Chem 1992;267:7856-7862.

13. Fuhrmann $\mathrm{K}$, Reiher $\mathrm{H}$, Semmler $\mathrm{K}$, et al. Prevention of congenital malformations in infants of insulin-dependent diabetic mothers. Diabetes Care 1983;6:219-223.

14. Martinez-Frias ML. Epidemiological analysis of outcomes of pregnancy in diabetic mothers: identification of the most characteristic and most frequent congenital anomalies. Am J Med Genet 1994;51:108-113.

15. Lynch SA, Wright C. Sirenomelia, limb reduction defects, cardiovascular malformation, renal agenesis in an infant born to a diabetic mother. Clin Dysmorphol 1997;6:75-80.

16. Amri K, Freund N, Vilar J, et al. Adverse effects of hyperglycemia on kidney development in rats: in vivo and in vitro studies. Diabetes 1999;48:2240-2245.

17. Brenner BM, Garcia DL, Anderson S. Glomeruli and blood pressure. Less of one, more the other? Am J Hypertens 1988;1:335-347.

18. Ingelfinger JR, Schnaper HW. Renal endowment: developmental origins of adult disease. J Am Soc Nephrol 2005;16:2533-2536.

19. Lelièvre-Pégorier $M$, Merlet-Benichou $C$. The number of nephrons in the mammalian kidney: environmental influences play a determining role. Exp Nephrol 2000;8:63-65.

20. Schrijvers BF, De Vriese AS, Flyvbjerg A. From hyperglycemia to diabetic kidney disease: the role of metabolic, hemodynamic, intracellular factors and growth factors/cytokines. Endocrine Rev 2004;25:971-1010.

21. Fornoni A, Striker LJ, Zheng F, et al. Reversibility of glucose-induced changes in mesangial cell extracellular matrix depends on the genetic background. Diabetes 2002;51:499-505.

22. McLennan SV, Fisher EJ, Yue DK, et al. High glucose concentration causes a decrease in mesangium degradation. A factor in the pathogenesis of diabetic nephropathy. Diabetes 1994;43:1041-1045.

23. McLennan SV, Wang XY, Moreno V, et al. Connective tissue growth factor mediates high glucose effects on matrix degradation through tissue inhibitor of matrix metalloproteinase type 1: implications for diabetic nephropathy. Endocrinology 2004;145:5646-5655.

24. Singh $\mathrm{R}$, Song $\mathrm{RH}$, Alavi $\mathrm{N}$, et al. High glucose decreases matrix metalloproteinase-2 activity in rat mesangial cells via transforming growth factor-beta1. Exp Nephrol 2001;9:249-257.

25. Kobayashi $\mathrm{T}$, Inoue $\mathrm{T}$, Okada $\mathrm{H}$, et al. Connective tissue growth factor mediates the profibrotic effects of transforming growth factor-beta produced by tubular epithelial cells in response to high glucose. Clin Exp Nephrol 2005;9:114-121.

26. Riser BL, Denichilo M, Cortes $\mathrm{P}$, et al. Regulation of connective tissue growth factor activity in cultured rat mesangial cells and its expression in experimental diabetic glomerulosclerosis. J Am Soc Nephrol 2000;11:25-38.

27. Roestenberg $P$, van Nieuwenhoven FA, Joles JA, et al. Temporal expression profile and distribution pattern indicate a role of connective tissue growth factor (CTGF/CCN-2) in diabetic nephropathy in mice. Am J Physiol Renal Physiol 2006;290:F1344-F1354.

28. Li JH, Huang XR, Zhu HJ, et al. Role of TGF-beta signaling in extracellular matrix production under high glucose conditions. Kidney Int 2003;63:2010-2019.

29. Kanwar YS, Liu ZZ, Kumar A, et al. D-glucose-induced dysmorphogenesis of embryonic kidney. J Clin Invest 1996;98:2478-2488.

30. Wada J, Kanwar YS, Makino H. Relevance of extracellular matrix and its receptors in mammalian nephrogenesis revealed by metanephric organ culture system. Nephrol Dial Transplant 2002;17(Suppl 9):75-77.

31. McVary KT, Maizels M. Urinary obstruction reduces glomerulogenesis in the developing kidney: a model in the rabbit. J Urol 1989;142:646651; discussion 67-68.

32. Vilar J, Gilbert T, Moreau E, et al. Metanephros organogenesis is highly stimulated by vitamin A derivatives in organ culture. Kidney Int 1996;49:1478-1487.

33. Guinobert I, Viltard M, Piquemal $D$, et al. Identification of differentially expressed genes between fetal and adult mouse kidney: candidate gene in kidney development. Nephron Physiol 2006;102:p81-p91.

34. Duong Van Huyen JP, Amri K, Belair MF, et al. Spatiotemporal distribution of insulin-like growth factor receptors during nephrogenesis in fetuses from normal and diabetic rats. Cell Tissue Res 2003:314:367-379.

35. Piedagnel R, Murphy G, Ronco PM, et al. Matrix metalloproteinase 2 (MMP2) and MMP9 are produced by kidney collecting duct principal 
cells but are differentially regulated by SV40 large-T, arginine vasopressin, and epidermal growth factor. J Biol Chem 1999;274: 1614-1620.

36. Lafont J, Jacques C, Le Dreau G, et al. New target genes for NOV/CCN3 in chondrocytes: TGF-beta2 and type X collagen. J Bone Miner Res 2005;20:2213-2223.

37. McCormick JJ, Blomquist JC, Rusch HP. Isolation and characterization of an extracellular polysaccharide from physarum polycephalum. J Bacteriol 1970;104:1110-1118.

38. Grobstein C, Cohen J. Collagenase: effect on the morphogenesis of embryonic salivary epithelium in vitro. Science 1965;150:626-628.

39. Wessells NK, Cohen JH. Effects of collagenase on developing epithelia in vitro: lung, ureteric bud, and pancreas. Dev Biol 1968;18:294-309.

40. Sakurai H, Nigam SK. Transforming growth factor-beta selectively inhibits branching morphogenesis but not tubulogenesis. Am J Physiol 1997;272:F139-F146.

41. Sakurai $H$, Barros EJ, Tsukamoto $T$, et al. An in vitro tubulogenesis system using cell lines derived from the embryonic kidney shows dependence on multiple soluble growth factors. Proc Natl Acad Sci USA 1997:94:6279-6284.
42. Shankland SJ, Ly H, Thai $\mathrm{K}$, et al. Glomerular expression of tissue inhibitor of metalloproteinase (TIMP-1) in normal and diabetic rats. J Am Soc Nephrol 1996;7:97-104.

43. Bush KT, Sakurai $H$, Steer DL, et al. TGF-beta superfamily members modulate growth, branching, shaping, and patterning of the ureteric bud. Dev Biol 2004;266:285-298.

44. Schmid P, Cox D, Bilbe G, et al. Differential expression of TGF beta 1 , beta 2 and beta 3 genes during mouse embryogenesis. Development 1991:111:117-130.

45. Vrljicak P, Myburgh D, Ryan AK, et al. Smad expression during kidney development. Am J Physiol Renal Physiol 2004;286:F625-F633.

46. Basile DP, Hammerman MR. TGF-beta in renal development and renal growth. Miner Electrolyte Metab 1998;24:144-148.

47. Rogers $\mathrm{SA}$, Ryan $\mathrm{G}$, Purchio AF, et al. Metanephric transforming growth factor-beta 1 regulates nephrogenesis in vitro. Am J Physiol 1993:264:996-F1002.

48. Amri K, Freund N, Van Huyen JP, et al. Altered nephrogenesis due to maternal diabetes is associated with increased expression of IGF-II/ mannose-6-phosphate receptor in the fetal kidney. Diabetes 2001;50:1069-1075. 